\title{
In vivo interactions of continuous flucloxacillin infusion and high-dose oral rifampicin in the serum of 15 patients with bone and soft tissue infections due to Staphylococcus aureus - a methodological and pilot study
}

Christian Garzoni ${ }^{1,2+}$, Ilker Uçkay ${ }^{1,3^{*}+}$, Wilson Belaieff ${ }^{3}$, Dominique Breilh $^{4}$, Domizio Suvà ${ }^{3}$, Elzbieta Huggler ${ }^{1}$, Daniel Lew ${ }^{1}$, Pierre Hoffmeyer ${ }^{3}$ and Louis Bernard ${ }^{3,5}$

\begin{abstract}
Background: Increased antibiotic resistance against Staphylococcus aureus and low penetration into bone requires regimen optimization of available drugs.

Methods: We evaluate pharmoacokinetic and pharmacodynamic parameters (PK/PD) as well as in vivo interactions of continuous flucloxacillin $12 \mathrm{~g} / \mathrm{d}$ administration combined with high dose oral rifampicin $600 \mathrm{mg}$ bid in the serum of 15 adult patients with bone and soft tissue infections. We use the patient's own serum directed against his own isolated S. aureus strain to reproduce in vivo conditions as closely as possible.

Results: The continuous flucloxacillin infusion constantly generated plasma free drug levels largely exceeding the serum minimal inhibitory concentrations (mean 74-fold). Combination with rifampicin significantly increased flucloxacillin levels by $44.5 \%$. Such an increase following rifampicin introduction was documented in 10/15 patients, whereas a decrease was observed in 1/15 patients. Finally, all infections were cured and the combination was well tolerated.

Conclusions: In this in vivo methodological pilot study among adult patients with orthopaedic infections due to $S$. aureus, we describe a new method and reveal substantial but inconsistent interactions between flucloxacillin and rifampicin, of which the clinical significance remains unclear.
\end{abstract}

Keywords: Flucloxacillin; Rifampicin; Synergism; Pharmacodynamics; Staphylococcus aureus

\section{Introduction}

Staphylococcus aureus is one of the most prevalent pathogen in bone and soft-tissue infections associated with and without foreign material. When implants are involved, $S$. aureus develops a biofilm in which most antimicrobial agents reveal inability to kill non-growing bacteria. The only clinically available exception is rifampicin/rifampin (Uçkay et al. 2009). Since rifampicin monotherapy may

\footnotetext{
* Correspondence: Ilker.Uckay@hcuge.ch

${ }^{\dagger}$ Equal contributors

'Department of Infectious Diseases, Geneva University Hospitals and Medical School, 4 Rue Gabrielle Perret-Gentil, 1211 Geneva, Switzerland

${ }^{3}$ Orthopaedic Surgery Department, Geneva University Hospitals and Medical

School, 4 Rue Gabrielle Perret-Gentil, 1211 Geneva, Switzerland

Full list of author information is available at the end of the article
}

lead to rapid emergence of rifampicin-resistant S. aureus, this drug should always be combined with other systemic antibiotics (Widmer et al. 1992; Zavasky and Sande 1998).

Continuous intravenous administration of a $\beta$-lactam antibiotics has been suggested more beneficial than intermittent drug use (Boselli et al. 2008; Drusano 2004; Landersdorfer et al. 2007). Flucloxacillin is a synthetic penicillinase-resistant penicillin similar to oxacillin or methicillin; with excellent anti-staphylococcal activity. For severe bone and soft tissue infections due to $S$. aureus, whether associated with orthopaedic implants or not, only limited data is currently available for flucloxacillin in continuous infusion alone (Howden and Richards 2001; Hackbarth et al. 1986; Leder et al. 1999) or in combination 
with rifampicin. Furthermore, development of new antimicrobial drugs against $S$. aureus by the industry is limited (Jugun et al. 2013). Therefore, new pharmacokinetic and pharmacodynamic (PK/PD) studies in vivo are required to optimize the potency of today's available antimicrobial regimens (Le and Bayer 2003; Czekaj et al. 2011). In this methodological and pilot study, we prospectively investigate activity parameters of a combined oral rifampicin and continuous flucloxacillin regimen in 15 adult hospitalized patients. Methodologically speaking, we use the patient's own serum directed against his own isolated $S$. aureus strain to reproduce in vivo conditions as closely as possible. This method may be clinically more relevant than in vitro studies on synergism/antagonism. Of note, this study wasn't designed to measure clinical outcome, and is focused on pharmocologic parameters in vivo only.

\section{Methods}

\section{Subjects and treatment}

Fifteen adult patients hospitalized for acute bone and soft tissue infections due to $S$. aureus were prospectively included in this methodological pilot study. Informed patient consent was obtained, in accordance with local institution policy. All subjects had microbiological identification of $S$. aureus in more than two concordant intraoperative bacterial cultures and a normal hepatic and renal function (creatinin-clearance $>50 \mathrm{ml} / \mathrm{min}$ ). Exclusion criteria were polymicrobial infections, co-medication with any drug known for significant interaction with rifampicin, patients with allergy or intolerance to flucloxacillin and/or rifampicin, and hepatitis (serum transaminase levels $>3 \times$ upper normal limit or cirrhosis CHILD B or C).

All patients were antibiotic-naïve prior to flucloxacillin/ rifampicin therapy being started. Continuous intravenous flucloxacillin $12 \mathrm{~g} / \mathrm{d}$ without loading dose was initiated as soon as $S$. aureus infection was suspected on the basis of a positive Gram-staining while awaiting culture pathogen identification. After $72 \mathrm{~h}$, flucloxacillin was considered at steady state, because of its serum half-life of 0.75-1.5 h. Oral rifampicin $600 \mathrm{mg}$ bid was added after culture confirmation and kept throughout the therapy. Duration of combined treatment with flucloxacillin and rifampicin followed current recommendations (Trampuz and Zimmerli 2006; Bernard et al. 2010). Surgery was performed according to standard of care. Staphylococci species were characterized by slidex agglutination (Pastorex $\left.{ }^{\circ}, \mathrm{BIO}-\mathrm{RAD}\right)$ and the ID32 Staphylococcus Gallery (bioMérieux, Marcy L'Etoile, France) and according to Clinical and Laboratory Standard Institute guidelines (CLSI 2008).

\section{Pharmacologic analyses}

Serum was collected at three predetermined time points. A: $72 \mathrm{~h}$ after initiation of flucloxacillin; B: at $48 \mathrm{~h}$ after rifampicin treatment onset but 30 minutes before the fifth dose was delivered (rifampicin trough level); C: 1 hour after fifth rifampicin dose (rifampicin peak level). At each time point, serum flucloxacillin $(A, B, C)$ and rifampicin $(B, C)$ concentrations were assessed using high liquid pressure chromatography technique. A specific and automatable assay was developed for simultaneous flucloxacillin and rifampicin quantification in human plasma. A Prontosil C18 AQ + $150 \times 4.6 \mathrm{~mm}$ column was used for chromatographic separation. Voriconazole was used as internal standard (IS). UV detection was set at three wavelengths: $220 \mathrm{~nm}$ for flucloxacillin, $340 \mathrm{~nm}$ for rifampicin and $260 \mathrm{~nm}$ for IS. Retention times were $3.8 \mathrm{~min}, 6 \mathrm{~min}$. and $7 \mathrm{~min}$. for flucloxacillin, rifampicin and IS respectively. Rifampicin and flucloxacillin were extracted from plasma and mixed with IS solution, an orthoboric acid $\mathrm{pH} 3.5$-solution and an ascorbic acid solution to prevent rifampicin oxidation. Limits of quantification and detection were $0.25-0.1 \mu \mathrm{g} / \mathrm{ml}$ for flucloxacillin, and 0.1 $0.03 \mu \mathrm{g} / \mathrm{ml}$ for rifampicin, respectively. Data's validation for accuracy in intra and inter-day precision were good. Coefficient of variation for flucloxacillin was between $3.43 \%$ and $8.58 \%$ and accuracy between $94.2 \%$ and $103.7 \%$. For rifampicin, the corresponding numbers were between $1.07 \%$ and $7.54 \%$ and between $96.0 \%$ and $106.4 \%$, respectively.

Flucloxacillin steady-state concentrations were measured before $600 \mathrm{mg}$ rifampicin was initiated (time point A) and at two time points afterwards (B and $\mathrm{C}$ ). The observed minimum and maximum concentrations of rifampicin were assumed to be at time point $B$ (trough level) and $C$ (peak level $1 \mathrm{~h}$ after), respectively. Steady-state concentration-time data for flucloxacillin were analyzed with a standard pharmacokinetic method by using Kinetica ${ }^{\text {mix }}$ software (Version 4.4, San Diego, USA). Steady-state concentration-time data for rifampicin were analyzed by population pharmacokinetic methods by using NPEM $^{\mathrm{m}}$ software (Los Angeles, USA).

\section{Serum minimal inhibitory concentration (SMIC) and bactericidal concentration (SMBC)}

For every patient, SMIC was determined at every time point using the microdilution method. Briefly, patient's serum was incubated for $24 \mathrm{~h}$ at $37^{\circ} \mathrm{C}$ after being added $10 \mathrm{E}^{6}$ colony forming units of $S$. aureus per serum milliliter. The $S$. aureus used was the same isolate that was isolated from the patient in question. SMIC was defined as the highest dilution that did not exhibit visible growth. Tests were performed in accordance with National Committee for Clinical Laboratory Standards recommendations (NCCLS 1999). The SMBC was defined as the concentration at which growth plates displayed killing $\geq 99.9 \%$ of the inoculum. All experiments for SMIC and SMBC were conducted in triplicate. 


\section{Statistical analysis}

Group comparisons were performed using the Wilcoxonranksum-test or the Kruskal-Wallis-test, as appropriate. $P$ values $\leq 0.05$ (two-tailed) were significant. Analyses were performed with STATA ${ }^{\text {tu }}$ software, 9.0 (Corporate Station, USA).

\section{Results}

\section{Patients and outcome}

A total of 15 patients (age, 35-75 years) with S. aureus infections were enrolled according to inclusion/exclusion criteria: 4 cellulitis with abscesses, 4 native joint infections, 3 infected orthopaedic implants, 2 spondylodiscitis, 2 bursitis and 1 case of pin-track infection with acute osteomyelitis. One patient had both cellulitis and osteomyelitis. Two episodes were bacteremic. Surgery was performed in all patients: drainage $(8 \times)$, debridement $(3 \times)$, bursectomy $(2 \times)$, one-stage prosthesis exchange $(1 \times)$ and pin removal (1x). All subjects completed the study and had complete infectious remission after the completion of therapy with a minimum follow-up of 12 months. Duration of treatment was variable according to the infection (14 to 41d, mean 23 days). All $S$. aureus strains were highly sensitive to both studied drugs. SMIC for flucloxacillin ranged between $0.25-1 \mu \mathrm{g} / \mathrm{ml}$ (mean $0.78 \mu \mathrm{g} / \mathrm{ml}$ ), and SMIC for rifampicin ranged between 0.015-0.03 $\mu \mathrm{g} / \mathrm{ml}$ (mean $0.019 \mu \mathrm{g} / \mathrm{ml}$ ) (CLSI 2008). Continuous flucloxacillin generated a mean serum level of $34 \mu \mathrm{g} / \mathrm{ml}$ (range 19.965.3). After adding rifampicin, on average flucloxacillin concentration increased significantly by $44.6 \%$ to a mean serum value of $45.6 \mu \mathrm{g} / \mathrm{ml}$ (range, 28.7-65.6) ( $p=0.0008$ ). In contrast, a highly significant difference was documented between SMIC at time point $\mathrm{A}$ and $\mathrm{C}$, with a mean value increasing from 1:130 to 1:412 $(p<0.001)$. Only one patient showed decreased activity after adding rifampicin (Table 1). There was no occurrence of significant medicamentous hepatitis with serum transaminases levels above the upper limit or liver insufficiency.

\section{Discussion}

We performed a methodological pilot study using the patient's own serum directed against his own isolated $S$. aureus strain to reproduce in vivo conditions as closely as possible. We furthermore demonstrate significant pharmacologic interaction during simultaneous administration of continuous $12 \mathrm{~g}$ per day flucloxacillin and oral rifampicin $600 \mathrm{mg}$ twice daily in 15 adult patients with various musculoskeletal infections due to S. aureus. Of note, our study did not demonstrate true synergism when using this combined regimen. The titer

Table 1 Reciprocal serum minimal inhibitory and bactericidal dilutions ${ }^{+}$

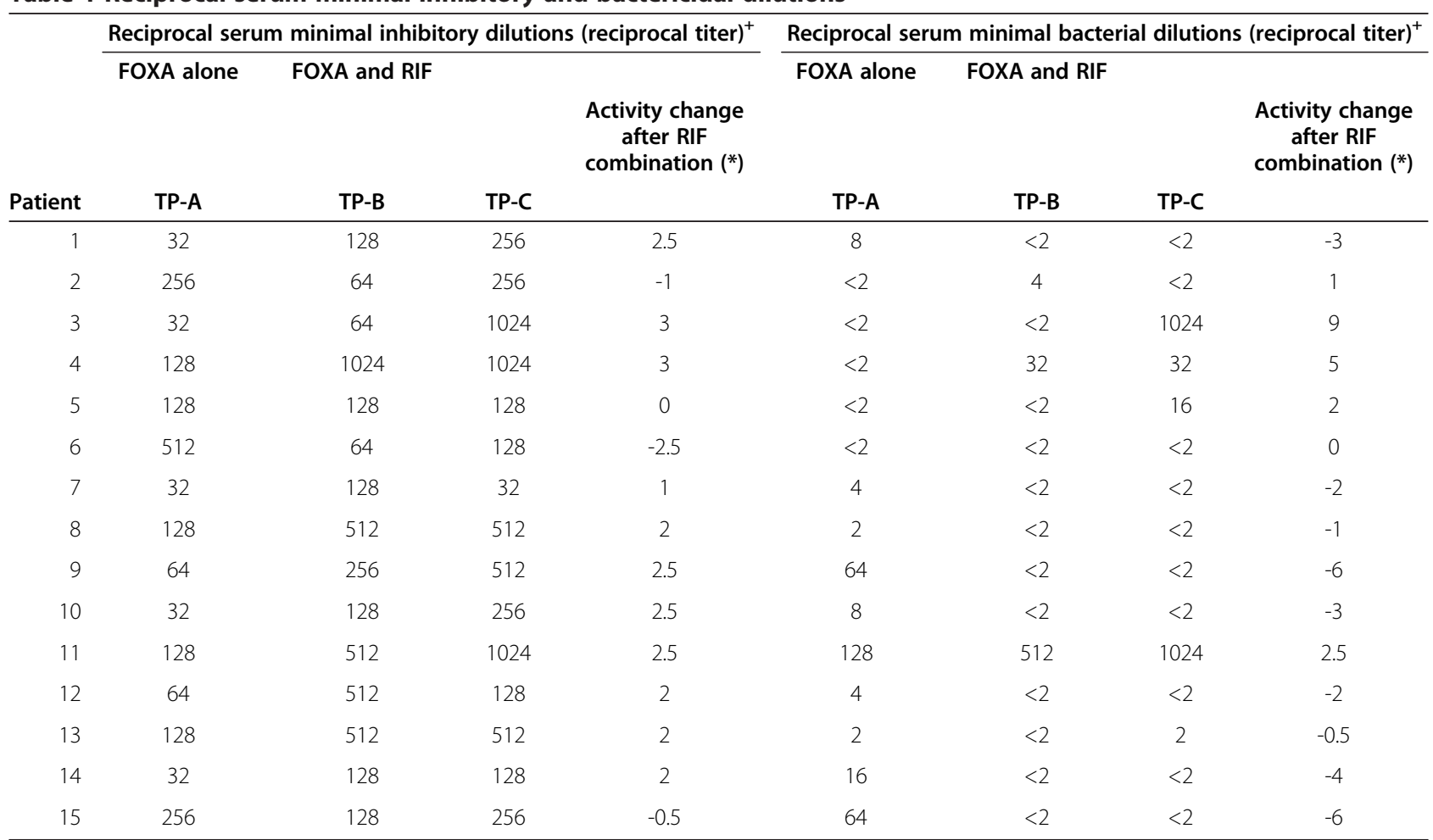

FOXA = Continuous intravenous flucloxacillin $12 \mathrm{~g} / \mathrm{d}$. RIF = Oral rifampin $600 \mathrm{mg}$ bid.

${ }^{+}$Units are not written to spare space. Units are in $\mu \mathrm{g} / \mathrm{ml}$.

*Activity change expressed in dilutions. Calculated as difference between activity with FOXA alone (time point A) and the mean activity in the 2 conditions

measured after RIF adjunction (time points B and C). Positive values denote increase activity, negative ones decreased activity. 
increase was only 3 -fold when two antibiotic treatments were administered simultaneously in comparison to one drug alone. There was a wide discrepancy between inhibitory and bactericidal serum dilutions in the majority of patients. This finding is inconsistent with what would be expected for bactericidal drugs in which the SMBC is usually within 4-fold of the SMIC.

Literature is controversial regarding synergism vs. antagonism of flucloxacillin combination with rifampicin/ rifampin (Brandt et al. 1994; Hackbarth et al. 1986; Massanari and Donta 1978; Swanberg and Tuazon 1984; Van der Auwera and Klastersky 1983; Van der Auwera et al. 1983, 1985; Zak et al. 1983; Zinner et al. 1981a, b). Overall, results between different in vitro studies correlate poorly and no single method has currently been proven superior to another (Bliziotis et al. 2007; Perlroth et al. 2008). Therefore, we have opted to study pharmagologic activities using the patient's own serum directed against his own isolated $S$. aureus strain to reproduce in vivo conditions as closely as possible. Thus, our method of testing patient's own serum with patient's own S. aureus is novel to the best of our knowledge. Most of our patients' serum collected under combined therapy showed enhanced antistaphylococcal flucloxacillin activity when tested in vitro. Sera collected at peak rifampicin concentration showed an increased, unchanged or decreased effect in 10 (67\%), 4 (27\%) and 1 (7\%) cases respectively, when compared with sera collected before rifampicin introduction.

In conclusion, we report that in continuous infusion with $12 \mathrm{~g} / \mathrm{d}$, serum flucloxacillin levels constantly exceeded by several folds the MIC for S. aureus and the association with rifampicin may further increase these serum levels. We also demonstrate that combination of rifampicin with a flucloxacillin may partially lead to an increased bactericidal effect, which was, however, not consistent in all patients. Our study used the patient's own serum directed against his own isolated $S$. aureus strain to reproduce in vivo conditions as closely as possible. The method used in the present study may be clinically more relevant than in vitro studies on synergism/antagonism. This was a methodological, pilot, and an in vivo pharmocologic study and not a clinical outcome study. All 15 patients were considered cured after a minimal follow-up of 12 months; however, our small cohort of patients makes it impossible to assess the clinical efficacy and relevance of our flucloxacillin and rifampicin serum interaction findings. Treatment may as well have been successful with a combination of surgery and flucloxacillin alone, particularly in the case of soft tissue infections such as cellulitis and bursitis.

\section{Competing interests}

The authors declared that they have no competing interests.

\section{Authors' contributions}

$C G, L B, I U$ and $D B$ designed the study. $C G, D B, D S, E H, D L$ and $P H$ conducted it. $C G, W B, L B$, and IU performed the drafting of the manuscript. All authors read and approved the final manuscript.

\section{Acknowledgements}

We thank the Laboratory of Microbiology of Geneva University Hospitals for the analyses.

\section{Funding}

No funding sources.

\section{Author details}

${ }^{1}$ Department of Infectious Diseases, Geneva University Hospitals and Medical School, 4 Rue Gabrielle Perret-Gentil, 1211 Geneva, Switzerland. ${ }^{2}$ Clinic for Infectious Diseases, University of Berne, Inselspital, Bern, Switzerland. ${ }^{3}$ Orthopaedic Surgery Department, Geneva University Hospitals and Medical School, 4 Rue Gabrielle Perret-Gentil, 1211 Geneva, Switzerland.

${ }^{4}$ Departments of Pharmacokinetics and Clinical Pharmacy, Victor-Segalen University, Bordeaux, France. ${ }^{5}$ Department of Infectious Diseases, Tours

University Hospital, Tours, France.

Received: 11 April 2014 Accepted: 22 May 2014

Published: 7 June 2014

\section{References}

Bernard L, Legout L, Zürcher-Pfund L, Stern R, Rohner P, Peter R, Assal M, Lew D, Hoffmeyer P, Uçkay I (2010) Six weeks of antibiotic treatment is sufficient following surgery for septic arthroplasty. J Infect 61:125-132

Bliziotis IAF, Ntziora F, Lawrence KR, Falagas ME (2007) Rifampin as adjuvant treatment of Gram-positive bacterial infections: a systematic review of comparative clinical trials. Eur J Clin Microbiol Infect Dis 26:849-856

Boselli E, Breilh D, Rimmele T, Guillaume C, Xuereb F, Saux MC, Bouvet L, Chassard D, Allaouchiche B (2008) Alveolar concentrations of piperacillin/ tazobactam administered in continuous infusion to patients with ventilatorassociated pneumonia. Crit Care Med 36:1500-1506

Brandt CM, Rouse MS, Tallan BM, Wilson WR, Steckelberg JM (1994) Failure of time-kill synergy studies using subinhibitory antimicrobial concentrations to predict in vivo antagonism of cephalosporin-rifampin combinations against Staphylococcus aureus. Antimicrob Agents Chemother 38:2191-2193

Clinical and Laboratory Standards Institute CLSI (2008) Performance Standards for Antimicrobial Susceptibility Testing; 17th Informational Supplement. Wayne, PA

Czekaj J, Dinh A, Moldovan A, Vaudaux P, Gras G, Hoffmeyer P, Lew D, Bernard L, Uçkay I (2011) Efficacy of a combined oral clindamycin-rifampicin regimen for therapy of staphylococcal osteoarticular infections. Scand J Infect Dis 43:962-967

Drusano GL (2004) Antimicrobial pharmacodynamics: critical interactions of 'bug and drug'. Nat Rev Microbiol 2:289-300

Hackbarth CJ, Chambers HF, Sande MA (1986) Serum bactericidal activity of rifampin in combination with other antimicrobial agents against Staphylococcus aureus. Antimicrob Agents Chemother 29:611-613

Howden BP, Richards MJ (2001) The efficacy of continuous infusion flucloxacillin in home therapy for serious staphylococcal infections and cellulitis. J Antimicrob Chemother 48:311-314

Jugun K, Vaudaux P, Garbino J, Pagani L, Hoffmeyer P, Lew D, Uçkay I (2013) The safety and efficacy of high-dose daptomycin combined with rifampicin for the treatment of Gram-positive osteoarticular infections. Int Orthop $37: 1375-1380$

Landersdorfer CB, Kirkpatrick CM, Kinzig-Schippers M, Bulitta JB, Holzgrabe U, Drusano GL, Sorgel F (2007) Population pharmacokinetics at two dose levels and pharmacodynamic profiling of flucloxacillin. Antimicrob Agents Chemother 51:3290-3297

Le T, Bayer AS (2003) Combination antibiotic therapy for infective endocarditis. Clin Infect Dis 36:615-621

Leder K, Turnidge JD, Korman TM, Grayson ML (1999) The clinical efficacy of continuous-infusion flucloxacillin in serious staphylococcal sepsis. J Antimicrob Chemother 43:113-118

Massanari RM, Donta ST (1978) The efficacy of rifampin as adjunctive therapy in selected cases of staphylococcal endocarditis. Chest 73:371-375 
National Committee for Clinical Laboratory Standards NCCLS (1999) Methodology for the Serum Bactericidal Test. Approved Standard M21-A. Wayne, PA

Perlroth J, Kuo M, Tan J, Bayer AS, Miller LG (2008) Adjunctive use of rifampin for the treatment of Staphylococcus aureus infections: a systematic review of the literature. Arch Intern Med 168:805-819

Swanberg L, Tuazon CU (1984) Rifampin in the treatment of serious staphylococcal infections. Am J Med Sci 287:49-54

Trampuz A, Zimmerli W (2006) Diagnosis and treatment of infections associated with fracture-fixation devices. Injury 37:59-66

Uçkay I, Pittet D, Vaudaux P, Sax H, Lew D, Waldvogel F (2009) Foreign body infections due to Staphylococcus epidermidis. Ann Med 41:109-119

Van der Auwera P, Klastersky J (1983) In vitro study of the combination of rifampin with oxacillin against Staphylococcus aureus. Rev Infect Dis 5:509-514

Van der Auwera P, Meunier-Carpentier F, Klastersky J (1983) Clinical study of combination therapy with oxacillin and rifampin for staphylococcal infections. Rev Infect Dis 5:515-522

Van der Auwera P, Klastersky J, Thys JP, Meunier-Carpentier F, Legrand JC (1985) Double-blind, placebo-controlled study of oxacillin combined with rifampin in the treatment of staphylococcal infections. Antimicrob Agents Chemother 28:467-472

Widmer AF, Gaechter A, Ochsner PE, Zimmerli W (1992) Antimicrobial treatment of orthopedic implant-related infections with rifampin combinations. Clin Infect Dis 14:1251-1253

Zak O, Scheld WM, Sande MA (1983) Rifampin in experimental endocarditis due to Staphylococcus aureus in rabbits. Rev Infect Dis 5:481-490

Zavasky DM, Sande MA (1998) Reconsideration of rifampin: a unique drug for a unique infection. JAMA 279:1575-1577

Zinner SH, Husson M, Klastersky J (1981a) Effect of mixing on rifampin bactericidal activity against staphylococci. Antimicrob Agents Chemother 20:267-269

Zinner SH, Lagast H, Klastersky J (1981b) Antistaphylococcal activity of rifampin with other antibiotics. J Infect Dis 144:365-371

\section{doi:10.1186/2193-1801-3-287}

Cite this article as: Garzoni et al:: In vivo interactions of continuous flucloxacillin infusion and high-dose oral rifampicin in the serum of 15 patients with bone and soft tissue infections due to Staphylococcus aureus - a methodological and pilot study. SpringerPlus 2014 3:287.

\section{Submit your manuscript to a SpringerOpen ${ }^{\circ}$ journal and benefit from:}

- Convenient online submission

- Rigorous peer review

- Immediate publication on acceptance

- Open access: articles freely available online

- High visibility within the field

- Retaining the copyright to your article

Submit your next manuscript at $\gg$ springeropen.com 